Goldschmidt 2021 Abstract

https://doi.org/10.7185/gold2021.5706

\section{Infrared spectroscopy of amphibole lamellae in pyroxenes from mantle xenoliths of the Carpathian- Pannonian region}

\author{
NORA LIPTAI ${ }^{1}$, THOMAS PIETER LANGE ${ }^{1,2}$, LEVENTE \\ PATKÓ $^{1,3,4}$, LÁSZLÓ ELŐD ARADI ${ }^{4}$, MARTA BERKESI ${ }^{4}$, \\ PETER M TOLLAN ${ }^{5,6}$, JOSÉ ALBERTO PADRÓN- \\ NAVARTA $^{7,8}$, JÖRG HERMANN ${ }^{9}$, CSABA SZABÓ ${ }^{3,4}$ AND \\ ISTVÁN JÁNOS KOVÁCS ${ }^{1}$ \\ ${ }^{1}$ MTA EK Lendület Pannon LitH2Oscope Research Group, \\ Centre for Energy Research \\ ${ }^{2}$ Eötvös Loránd University \\ ${ }^{3}$ Geodetic and Geophysical Institute, Research Centre for \\ Astronomy and Earth Sciences \\ ${ }^{4}$ Lithosphere Fluid Research Lab, Eötvös University \\ ${ }^{5}$ Institute of Geochemistry and Petrology, ETH Zürich \\ ${ }^{6}$ Institute of Geochemistry and Petrology, ETH Zurich \\ ${ }^{7}$ CNRS \& Univesité de Montpellier \\ ${ }^{8} \mathrm{CSIC}-\mathrm{UGR}$ \\ ${ }^{9}$ University of Bern \\ Presenting Author: n.liptai.elte@gmail.com
}

Amphibole has recently gained attention as a major water reservoir in the lithospheric mantle, since it was proposed that its breakdown at $\sim 3 \mathrm{GPa}$ or $\sim 1100^{\circ} \mathrm{C}$ [1] resulting in small degree partial melts may mark the lithosphere-asthenosphere boundary in areas with intermediate to high heat flow [2]. Amphibole in mantle peridotites frequently forms veins or appears as interstitial grains, commonly interpreted as products of modal metasomatism. Here we address the formation of another, rarely addressed form of mantle amphibole; lamellae within pyroxenes.

Fourier-transform infrared spectroscopy (FTIR) is widely used to characterise water content and distribution in nominally anhydrous minerals, however, most FTIR studies on amphiboles focus on spectral patterns of different, usually experimentally synthesised, amphibole compositions. There are only a small number of infrared studies on natural amphiboles [3], especially on lamellae, although hyperspectral imaging is a powerful tool to map the distribution of amphibole lamellae or other waterbearing phases in mantle pyroxenes.

In our study, we present hyperspectral FTIR maps obtained with a high-resolution ( $\mu \mathrm{m}$-scale) focal plane array detector showing the distribution of amphibole lamellae within ortho- and clinopyroxenes, and compare it with infrared spectra of natural mantle amphiboles from various tectonic environments from the Carpathian-Pannonian region. It was previously thought that the lamellae form with subsolidus exsolution upon entering the amphibole stability field, however, the scarcity of lamellahosting grains suggests that this may not happen uniformly in the peridotite, even if the pyroxenes are water-rich. We suggest that an additional source of water is needed locally for the amphibole lamellae to form, which could be a neighbouring interstitial amphibole, fluid inclusions, or metasomatic melts/fluids on the grain boundary.
[1] Green et al. (2010), Nature, 467, 448-451.

[2] Kovács et al. (2017), Acta Geodaetica et Geophysica, 52, 183-204.

[3] Della Ventura et al. (2007), American Mineralogist, 92, 1645-1651. 